\title{
DETERMINANTES DA ADOÇÃO DO COMITÊ DE AUDITORIA EM EMPRESAS BRASILEIRAS LISTADAS NA B3
}

DETERMINANTS OF THE ADOPTION OF THE AUDIT COMMITTEE IN BRAZILIAN COMPANIES LISTED ON B3

\section{ALINI DA SILVA ${ }^{1}$ \\ JÚLIO CESAR LOPES DE SOUZA² \\ NELSON HEIN ${ }^{3}$}

\begin{abstract}
RESUMO: O presente estudo teve por objetivo analisar os determinantes da adoção do comitê de auditoria em empresas brasileiras listadas na B3. Para tanto a metodologia adotada foi descritiva, documental e quantitativa. A amostra do estudo corresponde a 534 observações de empresas no período de 2010 a 2015. Para a análise dos dados utilizou-se de estatística descritiva, para caracterizar as variáveis e de regressão logística (software SPSS). Os achados evidenciaram que empresas maiores, com melhor retorno das ações e oportunidade de crescimento, possuem a tendência de adotar o comitê de auditoria em sua estrutura organizacional, enquanto que empresas auditadas pelas principais empresas globais de auditoria, as "Big Four", Deloitte, Ernst \& Young, KPMG e PricewaterhouseCoopersPwC, tiveram associação maior com a ausência do comitê de auditoria. Estes resultados revelam a tendência de empresas que possuem complexidade em sua estrutura, que são bem negociadas no mercado e que se encontram em expansão no mercado, terem controles formalizados por meio do comitê de auditoria para continuarem no mercado de maneira eficiente. Dessa forma, o resultado do retorno da ação revela que empresas com grandes retornos de suas ações possuem pressão dos investidores de terem boas práticas e controles internos eficazes para continuar sua negociação, o que tem influência na decisão da empresa em formalizar o comitê de auditoria, mesmo nas que não possuem obrigação legal para tal.
\end{abstract}

Palavras-chave: Comitê de auditoria. Adoção do Comitê de Auditoria. Empresas Brasileiras.

ABSTRACT: The present study aimed to analyze the determinants of the adoption of the audit committee in Brazilian companies listed on B3. For this, the methodology adopted was descriptive, documentary and quantitative. The sample of the study corresponds to 534 observations of companies in the period from 2010 to 2015. For the data analysis we used descriptive statistics to characterize the variables and logistic regression (SPSS software). The findings showed that larger companies with better stock returns and growth opportunities tended to adopt the audit committee in their organizational structure, while companies audited by leading global audit firms, the Big Four, Deloitte, Ernst \& Young, KPMG and PricewaterhouseCoopersPwC, were more closely associated with the absence of the audit committee. These results reveal the tendency of companies that have complexity in their structure, which are well-traded in the market and that are expanding in the market, have controls formalized through the audit committee to continue in the market in an efficient

\footnotetext{
Data de submissão: 24/10/2017 Data de aceite: 18/09/2018 Data de publicação: 28/09/2018

${ }^{1}$ Doutoranda em Ciências Contábeis e Administração - Universidade Regional de Blumenau

2 Doutorando em Ciências Contábeis e Administração - Universidade Regional de Blumenau

${ }^{3}$ Professor no Programa de Pós Graduação em Ciências Contábeis - Universidade Regional de Blumenau
} 
way. Thus, the stock return results reveal that companies with high returns from their shares are under pressure from investors to have good practices and effective internal controls to continue trading, which has an influence on the company's decision to formalize the audit committee, even in those with no legal obligation to do so.

Keywords: Audit Committee. Adoption of the Audit Committee. Brazilian Companies.

\section{INTRODUÇÃo}

Escândalos corporativos vultosos tais como o que ocorreram em empresas estadunidenses como Enron, Tyco e WorldCom, nos primeiros anos da década de 2.000, afetaram significativamente a dinâmica do mercado global, tanto pelos prejuízos financeiros quanto pela quebra de confiança. A origem desse fenômeno é relacionada a problemas com os controles internos das organizações ou mesmo sua ausência, que fizeram com que órgãos reguladores como a Securities and Exchange Commission (SEC), a comissão de valores mobiliários dos Estados Unidos, tornassem mais rígidas as regras para as empresas quanto a governança corporativa (HOGAN; WILKINS, 2008).

Os fatos envolvidos nesse contexto acabaram por influenciar negativamente empresas de auditoria anteriormente reconhecidas pela idoneidade, como a Arthur Andersen, que teve interrompida suas atividades de auditoria em decorrência de envolvimento em escândalo financeiro. Isso resultou na queda da credibilidade das empresas especializadas em auditagem, ocasionando a concentração das atividades de auditoria das grandes corporações internacionais em quatro firmas apenas, conhecidas como "Big Four": Deloitte, Ernst \& Young, KPMG e PricewaterhouseCoopersPwC (VELOZO; PINHEIRO; SANTOS, 2013).

Esse contexto propiciou a percepção da necessidade de maior rigor nas ações de governança corporativa, inclusive com a adoção de formas alternativas à auditoria externa. Dessa forma a estruturação de comitês responsáveis pela auditoria interna ganhou espaço, dotados de estruturas, autonomia e com características específicas (VELOZO; PINHEIRO; SANTOS, 2013).

O recrudescimento das atividades de governança corporativa foi articulado ao mesmo tempo que a regulamentação específica foi criada, buscando evitar novos eventos críticos que comprometessem a continuidade das empresas no mercado. Quanto a esta regulamentação, a Securities and Exchange Commission (SEC) criou a Lei Sarbanes-Oxley (SOX), sancionada pelo congresso estadunidense em 30 de julho de 2002, que obriga as empresas daquele país a adotarem diversas práticas e controles internos, inclusive em relação à implantação de comitê de auditoria nas empresas, a fim de se ter maiores recursos de controle e gestão. A SOX exige que empresas brasileiras que possuem negociação de ações na bolsa de valores dos Estados Unidos realizem a constituição e o funcionamento desse comitê (PELEIAS; SEGRETI; COSTA, 2009).

O comitê de auditoria, para a governança corporativa, é um dos principais mecanismos de proteção aos usuários da empresa, contra comportamentos oportunistas de agentes (GOODWIN-STEWART; KENT, 2006). Este comitê auxilia na revisão de informações contábeis, controle interno, métodos e políticas da empresa, bem como examinam as demonstrações financeiras e relatórios da auditoria (PINCUS; RUSBARSKY; WONG, 1989; BRADBURY, 1990; MENON; WILLIAMS, 1994). 
No cenário de empresas brasileiras, a Comissão de Valores Mobiliários (CVM) recomenda que não só as que possuem negociação nos Estados Unidos, mas que as demais, também implantem este comitê, ou que adaptem o comitê fiscal com funções do de auditoria, porém, não torna obrigatória a adoção deste comitê no cenário nacional para todos os setores. Entretanto, observa-se um número considerável de empresas listadas na B3 S.A. Brasil, Bolsa, Balcão, em torno de 60 empresas, que possuem comitê de auditoria.

Desta forma, diante desta problemática, destaca-se como problema de pesquisa: Quais são os determinantes da adoção do comitê de auditoria em empresas brasileiras listadas na B33? A fim de auxiliar na resolução deste problema tem-se como objetivo de estudo analisar os determinantes da adoção do comitê de auditoria em empresas brasileiras listadas na B3.

As empresas brasileiras não possuem uma regulação externa que as obriguem a adotar o comitê de auditoria em sua governança corporativa, em que as empresas que criaram este comitê em sua organização, estão o realizando de forma voluntária, salvo setores como financeiras, estatais, por exemplo, as quais possuem legislação específica, o que torna oportuna a investigação dos determinantes da adoção deste tipo de comitê.

Estudos de Pincus, Rusbarsky e Wong (1989), Furuta (2010), Cunha e Politelo (2013) e Freitas Neto e Mol (2017) avaliaram determinantes da adoção do comitê de auditoria, comitê fiscal ou governança corporativa. Pincus, Rusbarsky e Wong (1989), anterior à lei SOX, investigaram por que algumas empresas adotaram voluntariamente comitês de auditoria, enquanto outros não, no cenário norte-americano. Furuta (2010) analisou as características de empresas brasileiras que as levaram a optar em formar o comitê de auditoria ou adaptar o conselho fiscal, no período de 2005 a 2008. Cunha e Politelo (2013) investigaram a partir de um ranking de governança corporativa, quais características determinam a adoção de mecanismos de governança corporativa pelas empresas de capital aberto listadas na B3 que compõem o setor de consumo cíclico.

Desta forma, este estudo busca preencher, a nível nacional, a lacuna de pesquisa quanto a esta investigação dos determinantes da adoção do comitê de auditoria em período mais recente de 2010 a 2015, contribuindo com os estudos já realizados e expande as evidências encontradas até então, por serem analisados todos os setores listados na bolsa de valores.

Os resultados da presente pesquisa podem beneficiar organismos reguladores como governança corporativa, auditoria independente, comissão de valores mobiliários, instituto brasileiro de governança corporativa, entre outros, ao demonstrar possíveis influenciadores para a adoção do comitê de auditoria, podendo então incentivar e auxiliar o desenvolvimento de tais fatores em empresas, contribuindo para a tomada de decisão da adoção de tal.

Além disso, alerta-se os usuários da informação contábil, como clientes, fornecedores, bancos, investidores, entre outros, quanto a características de empresas que podem as levar a um maior nível de confiabilidade de processos internos, devido a propensão da adoção do comitê de auditoria em sua estrutura de governança corporativa. Assim, empresas com tais características podem reforçar sua credibilidade perante os usuários internos e externos. 


\section{REFERENCIAL TEÓRICO}

Apresentam-se nesta seção as principais referências acerca da origem e importância do comitê de auditoria nas empresas, bem como os determinantes da adoção do comitê de auditoria nas organizações, que se fazem necessárias para o embasamento teórico da presente pesquisa.

\subsection{Origens e importância do comitê de auditoria nas empresas}

A partir dos anos 2.000 o mercado financeiro e de capitais atravessou por intensa crise mundial de credibilidade, face aos escândalos financeiros surgidos a partir de fraudes contábeis. O insucesso de renomadas empresas como Enron, Tyco e WorldCom, consideradas até então modelos de boa gestão, tornou necessária a discussão e adoção de mecanismos de controle prescrito pela governança corporativa (WILKS; ZIMBELMAN, 2004; MURCIA; BORBA, 2005; BELLI et al., 2016).

O mercado financeiro de capitais requer transparência e a governança corporativa se propõe a zelar pela transparência das informações contábeis apresentadas ao público. A partir dessa perspectiva, comitês de assessoramento aos conselhos de administração surgiram, de forma a minorar os riscos que as empresas e seus investidores estavam expostos (BEUREN et al., 2013). Adicionalmente, autores como Correia e Amaral (2008) reconhecem que o surgimento da governança corporativa partiu também da necessidade de se tornar mínimo os conflitos de agência gerados entre os acionistas (principal) e os administradores (agentes), integrando os objetivos conflitantes dos diversos participantes em um contexto contratual legal.

Esse contexto propiciou o surgimento de regramento específico a respeito no continente europeu e nos Estados Unidos, notoriamente a lei proposta pelo senador Paul Sarbanes e o deputado Michael Oxley, políticos estadunidenses, norma sancionada em julho de 2002. Essa lei, também conhecida como Public Company Accouanting Reform and Investor Protection Act, habitualmente conhecida como SOX, promoveu alterações nos procedimentos e no controle da administração de empresas, órgãos reguladores responsáveis pelo estabelecimento de normas, comitês de auditoria e a participação de firmas de auditoria independente na análise da empresa (BORGES, 2008).

Segreti e Costa (2007) mencionam que, de acordo com a SOX, as empresas não americanas, como as brasileiras, que têm títulos negociados no mercado norte-americano de capitais (American Depositary Receipts - ADRs) estão obrigadas a atender a todos os preceitos daquela lei. Dessa forma, o impacto do movimento de busca por rigor e precisão na construção de informações contábeis ficou evidenciado no Brasil.

Esse movimento para fortalecimento das práticas de governança corporativa teve desdobramentos evidentes, encontrando amparo na ação de outra instância de referência, a Organização para a Cooperação e Desenvolvimento Econômico (OCDE). A OCDE que tem como a missão promover políticas que melhorem o bem-estar econômico e social em todo o mundo e, a partir de 1999, passou a promover reuniões em todo para definir princípios de governança corporativa para cada região, considerando suas peculiaridades e características.

A rodada de reuniões entre 2003 e 2004 gerou um documento que preconizava seis princípios: (1) constituição de base para uma estrutura de governança corporativa eficaz, (2) garantia dos direitos dos acionistas e funções-chave de propriedade, (3) tratamento equitativo dos acionistas, (4) definição do papel das partes interessadas em governança 
corporativa, (5) evidenciação e transparência e (6) definição das responsabilidades do conselho, conforme Organisation For Economic Co-Operation And Development (2004).

A governança corporativa envolve um conjunto de procedimentos que buscam dar rigor e precisão requeridos, alinhando a gestão com o interesse dos acionistas, constituindo um sistema pelo qual as organizações são dirigidas, monitoradas e incentivadas. Esse contexto envolve os relacionamentos entre proprietários, conselho de administração, diretoria e órgãos de controle (INSTITUTO BRASILEIRO DE GOVERNANÇA CORPORATIVA, 2015). Essa estrutura oferece ordenamento ao conjunto de informações financeiras, propiciando objetividade, recomendações e conformidade com os interesses entre os agentes envolvidos. $O$ objetivo é tornar mínimos os conflitos de interesse e as quebras do dever fiduciário (VERA-MUNÕZ, 2005).

A adoção dos comitês de assessoramento aos conselhos de administração, como o comitê de auditoria, é considerada boa prática, porque propicia o aprofundamento da compreensão de temas pertinentes às decisões do conselho de administração, que não se exime da responsabilidade plena sobre os assuntos tratados pelo comitê, que atua como apoio do conselho (SHARMA; NAIKER; LEE, 2009).

A importância do comitê de auditoria é evidenciada a partir de sua amplitude de atuação e suas atribuições são orientadas pela Lei Sarbanes-Oxley e pelas normativas do Banco Central do Brasil (BACEN), com os devidos acréscimos das resoluções 3.081/03 e 3.170/04, que adicionaram detalhes que não são abordados pela legislação americana. São exemplos dessas especificidades, as reuniões do comitê com o conselho fiscal e a obrigatoriedade de elaboração de um relatório do comitê de auditoria semestralmente, conforme o artigo 16 da Resolução 3.081/03 (OLIVEIRA; COSTA, 2005).

De uma maneira abrangente a regulamentação aplicada aos Comitês de Auditoria tem evoluído substancialmente de forma global e, no Brasil, a legislação converge para a determinação das funções atribuídas ao Conselho de Administração e, da mesma forma, ao Comitê de Auditoria, este que assume posição essencial na supervisão de funções extremamente críticas das organizações, de acordo com o Instituto Brasileiro de Governança Corporativa (2015).

\subsection{Determinantes do comitê de auditoria}

A lei Sarbanes-Oxley/SOX dos Estados Unidos foi uma das exemplificações de um cenário desregulamentado para regulamentado em relação a algumas práticas de governança corporativa e comitê de auditoria. A SOX trouxe abordagens rígidas de regulação e prestação de contas, exigindo que empresas americanas ou que estão listadas na bolsa de valores dos EUA tenham formado o comitê de auditoria (BAIOCO; ALMEIDA, 2017).

Furuta (2010) esclarece que o objetivo principal da norma foi dar credibilidade aos registros financeiros e contábeis, diminuindo ameaças ao capital investido. Entretanto, para as empresas brasileiras negociadas na bolsa dos EUA, a Securities and Exchange Commssion/SEC, órgão regulador do mercado de capitais estadunidense, permitiu a possibilidade da adaptação do conselho fiscal para atuar como comitê de auditoria, assumindo suas funções, caso a empresa assim tomasse esta decisão.

A Comissão de Valores Mobiliários (CVM), devidamente inspirada pela SOX, tem incentivado os empreendimentos brasileiros a implantar o comitê de auditoria ou adaptar seu conselho fiscal, mesmo que estas empresas não tenham negociação nas bolsas de valores dos EUA (PELEIAS; SEGRETI; COSTA, 2009). Isto ocorreu em decorrência de escândalos corporativos ocorridos nos últimos anos, o que gera preocupação para o 
mercado de capitais e as empresas em relação aos problemas de governança, que podem determinar o fim da continuidade de uma entidade (FURUTA, 2010). A formação do comitê de auditoria nas empresas pode auxiliar na preservação desta e continuidade no mercado.

Assim, mesmo para as empresas que operam somente na bolsa de valores nacional, embora tenha adesão voluntária, a implantação do comitê de auditoria se tornou boa prática de gestão, porque se caracteriza em instrumento de fator de aproximação e confiança entre as partes interessadas. Desse contexto, surgiram pesquisas com o intuito de verificar em cenários sem a obrigação de implantação do comitê de auditoria, quais os motivos que levam as empresas a adotarem este comitê, ou seja, os determinantes da adoção de tal comitê.

Pincus, Rusbarsky e Wong (1989), anterior à lei SOX, investigaram por que algumas empresas adotaram voluntariamente comitês de auditoria, enquanto outras não, no cenário norte-americano. Os autores observaram que as empresas adotaram o comitê de auditoria quando gestores das empresas possuem menor concentração de ações, quando a empresa possui maior alavancagem, maior tamanho e quando são auditadas pelas "Big Four".

Os motivos dessa concentração foram estudados por Dantas et al. (2012) que, ao analisarem relatório emitido pelo Government Accountability Office (GAO) em 2008, constataram que a preferência pela contratação das "Big Four" estava relacionada à percepção de que as firmas de auditoria de menor porte talvez não teriam a capacidade e expertise técnica que elas esperam de um auditor. Dantas et al. (2012) mencionam ainda que no mercado inglês, as "Big Four" auditam 99 das 100 empresas que compõe o índice Financial Times Stock Exchange (FTSE 100), com as cem ações mais representativas da bolsa de Londres. Já a respeito do índice FTSE 250, 240 são auditadas por elas.

Adams (1997) examinou empiricamente os determinantes da formação do comitê de auditoria em empresas de seguros de vida da Nova Zelândia. Quanto aos procedimentos metodológicos utilizou, como variável dependente, a presença ou não de comitê de auditoria nas empresas, representado por variável dummy, e como variáveis independentes (determinantes da adoção do comitê de auditoria), utilizou as variáveis de tamanho da empresa, alavancagem, custo de monitoramento, entre outros. Os resultados demonstraram que os comitês de auditoria se associaram positivamente com as grandes empresas, com a alavancagem e gastos elevados com monitoramento.

Cunha e Politelo (2013) investigaram, a partir de uma classificação de governança corporativa, as características determinam a adoção de mecanismos de governança corporativa pelas empresas de capital aberto listadas na B3 que compõem o setor de consumo cíclico. Os resultados evidenciaram que investidores institucionais impactaram negativamente no nível de governança corporativa, a oportunidade de investimento e crescimento da empresa impactaram positivamente nos níveis de governança corporativa, também constataram que o tamanho da empresa e o grau de intangibilidade impactaram a adoção de melhores práticas de governança corporativa.

Furuta (2010) analisou as características de empresas brasileiras que as levaram a optar em formar o Comitê de Auditoria ou adaptar o Conselho Fiscal, sob o ponto de vista da teoria da agência, no período de 2005 a 2008. Para medir a presença de Comitê de Auditoria ou Comitê Fiscal, foi atribuída uma variável dummy, as variáveis independentes utilizadas para verificar se eram determinantes para a adoção do comitê de auditoria foram: tamanho da empresa, alavancagem da empresa, governança corporativa, tipo de empresa de auditoria (big four), retorno da ação, entre outras variáveis. Os resultados evidenciaram que quanto maior a empresa, maior é a tendência de possuírem Comitê de Auditoria, verificaram 
que empresas participantes no Novo Mercado ou no nível 2 de Governança Corporativa apresentaram maior tendência de terem Comitê de Auditoria, também empresas que eram auditadas por Big Four possuíam Comitê de Auditoria, por fim verificaram também que empresas que possuíam retornos positivos das ações estavam associadas com a presença do Comitê de Auditoria.

\section{PROCEDIMENTOS METOdOLÓGICOS}

A presente pesquisa quanto ao objetivo de analisar os determinantes da adoção do Comitê de Auditoria em empresas brasileiras, configura-se como descritiva. Quanto aos procedimentos da pesquisa enquadra-se como documental, com a análise de informações em relatórios financeiros e formulários de referências das empresas. $E$ em relação à abordagem do problema configura-se como quantitativo, devido à utilização de técnicas estatísticas para a análise de dados.

\subsection{População e Amostra}

A população do estudo compreendeu todas as empresas listadas na Bolsa de Valores Mercadorias e Futuros de São Paulo - B3. A amostra é composta por empresas, que dispunham de todas as informações necessárias para a análise dos dados, que constituíram 534 observações no período de análise de 2010 a 2015. Destas 534 observações 267 referiram-se a empresas que possuíam Comitê de Auditoria e da mesma forma utilizou-se de outras 267 observações de empresas que não possuíam Comitê de Auditoria (escolhidas aleatoriamente). A composição de amostras iguais para cada grupo foi considerada necessária para se realizar regressão logística.

\subsection{Coleta e Análise dos Dados}

A coleta de dados se deu por meio da base Economática, a fim de identificar alguns determinantes da adoção do comitê de auditoria e também dos formulários de referências das empresas, necessárias para se verificar o tipo de auditoria, se a empresa possuía algum nível de governança corporativa, bem como, para se verificar se a empresa possuía Comitê de Auditoria. Na Tabela 1 apresentam-se as variáveis do estudo, fórmulas, local de coleta e, os autores de estudos relacionados.

As variáveis constantes na Tabela 1 foram analisadas por meio de estatística descritiva e regressão logística, por meio do software SPSS, versão XX. A regressão logística foi operacionalizada pelo modelo 1.

$$
P C A=\frac{1}{1+\epsilon^{-(\beta 0+\beta 1 T A M+\beta 2 A+\beta 3 G I+\beta 4 G T+\beta 5 R A+\beta 6 O C+\beta 7 G C+\beta 8 B F)}}
$$

Com base no modelo 1 , analisou-se os determinantes para as empresas brasileiras analisadas, no período de 2010 a 2015, de implantação do comitê de auditoria. A variável dependente é a presença ou não do Comitê de Auditoria nas empresas e, as variáveis independentes, tem-se o tamanho da empresa, alavancagem, grau de intangibilidade, grau de tangibilidade, retorno da ação, se a empresa possui governança corporativa e, se é auditada pelas Big Four. Utilizou-se de tais fatores determinantes, de acordo com a literatura, com o intuito de explicar a adoção do Comitê de Auditoria pelas empresas. 
Tabela 1 - Constructo da pesquisa

\begin{tabular}{|c|c|c|c|}
\hline Variável & Descrição & Origem dos Dados & Autores \\
\hline \multicolumn{4}{|c|}{ Variável Dependente } \\
\hline $\begin{array}{l}\text { Presença de } \\
\text { Comitê de } \\
\text { Auditoria (PCA) }\end{array}$ & $\begin{array}{l}\text { Variável dummy, sendo que } 1 \\
\text { representa a presença de comitê } \\
\text { de auditoria nas empresas, caso } \\
\text { contrário é representada por } 0 .\end{array}$ & $\begin{array}{l}\text { B3: Formulário de } \\
\text { Referência } 12.7- \\
\text { Composição dos } \\
\text { Comitês. }\end{array}$ & $\begin{array}{l}\text { Adams (1997) Furuta } \\
\text { (2010) }\end{array}$ \\
\hline \multicolumn{4}{|c|}{ Variáveis Independentes } \\
\hline $\begin{array}{l}\text { Tamanho da } \\
\text { empresa (TAM) }\end{array}$ & $\begin{array}{l}\text { Logaritmo natural do total de ativos } \\
\text { da empresa. }\end{array}$ & Economática & $\begin{array}{c}\text { Adams (1997) Furuta } \\
\text { (2010) } \\
\text { Cunha e Politelo } \\
\text { (2013) }\end{array}$ \\
\hline Alavancagem (A) & $\begin{array}{l}\text { Soma do passivo circulante e não } \\
\text { circulante (dívidas totais) em } \\
\text { relação ao ativo total da empresa. }\end{array}$ & Economática & $\begin{array}{c}\text { Adams (1997), Furuta } \\
\text { (2010). }\end{array}$ \\
\hline $\begin{array}{c}\text { Grau de } \\
\text { intangibilidade (GI) }\end{array}$ & $\begin{array}{l}\text { Relação do ativo intangível com o } \\
\text { total de ativos. }\end{array}$ & Economática & $\begin{array}{c}\text { Cunha e Politelo } \\
\text { (2013). }\end{array}$ \\
\hline $\begin{array}{c}\text { Grau de } \\
\text { tangibilidade (GT) }\end{array}$ & $\begin{array}{l}\text { Relação do ativo imobilizado com o } \\
\text { total de ativos. }\end{array}$ & Economática & $\begin{array}{l}\text { Adaptado de Cunha e } \\
\text { Politelo (2013). }\end{array}$ \\
\hline $\begin{array}{l}\text { Retorno da Ação } \\
\text { (RA) }\end{array}$ & $\begin{array}{l}\text { Relação do preço da ação no final } \\
\text { de } t_{i} \text { com o preço da ação no final } \\
\text { de } t_{i-1} \text {. }\end{array}$ & Economática & Furuta (2010). \\
\hline $\begin{array}{l}\text { Oportunidade de } \\
\text { Crescimento (OC) }\end{array}$ & $\begin{array}{l}\text { Relação das vendas no final de } t_{i} \\
\text { com as vendas no final de } t_{i-1} \\
\text { diminuído das vendas no final de } t_{i-1}\end{array}$ & Economática & $\begin{array}{l}\text { Cunha e Politelo } \\
\text { (2013). }\end{array}$ \\
\hline $\begin{array}{c}\text { Governança } \\
\text { Corporativa (GC) }\end{array}$ & $\begin{array}{l}\text { Variável dummy, em que } 1 \\
\text { representa a presença da empresa } \\
\text { em algum nível de Governança } \\
\text { Corporativa e } 0 \text { caso contrário. }\end{array}$ & B3 & Furuta (2010). \\
\hline $\begin{array}{l}\text { Tipo de Empresa } \\
\text { de Auditoria (BF) }\end{array}$ & $\begin{array}{l}\text { Variável dummy, em que } 1 \\
\text { representa a empresa sendo } \\
\text { auditada por uma Big Four e } 0 \text { caso } \\
\text { contrário. }\end{array}$ & $\begin{array}{l}\text { B3: FR 2.1/2 - } \\
\text { Identificação e } \\
\text { Remuneração } \\
\text { Auditores } \\
\text { Independentes. }\end{array}$ & Furuta (2010). \\
\hline
\end{tabular}

Fonte: Dados da pesquisa.

\section{DESCRIÇÃO E ANÁLISE DOS DADOS}

A Tabela 2 apresenta a análise da estatística descritiva das variáveis do estudo, a fim de se observar o mínimo, máximo, média e desvio padrão dos dados. Nesta análise não se consideraram as variáveis dicotômicas, tais como presença do comitê de auditoria, governança corporativa e empresas auditadas pelas Big Four, visto que variam somente de 0 a 1, não havendo a necessidade de se avaliar sua estatística descritiva.

Tabela 2 - Análise descritiva das variáveis

\begin{tabular}{l|c|c|c|c}
\hline \multicolumn{1}{c|}{ Variáveis } & Mínimo & Máximo & Média & $\begin{array}{c}\text { Desvio- } \\
\text { Padrão }\end{array}$ \\
\hline Tamanho da empresa logaritimizado (TAM) & 6,357842 & 21,086161 & 15,623668 & 1,908564 \\
Alavancagem da empresa (A) & 0,099688 & 144,411443 & 1,513316 & 9,360986 \\
Grau de intangibilidade (GI) & 0,000017 & $3.884,410686$ & 13,862890 & 212,845402 \\
Grau de tangibilidade (GT) & 0,000002 & 0,807088 & 0,213431 & 0,205324 \\
Retorno por ação (RA) & $-0,992986$ & 109,098230 & 0,171123 & 4,821628 \\
Oportunidade de crescimento (OC) & $-0,998885$ & 109,771104 & 0,360718 & 4,823496 \\
\hline
\end{tabular}

Fonte: Dados da pesquisa. 
Com base na Tabela 2, pode-se observar que o desvio padrão do tamanho da empresa é baixo, o que demonstra pouca dispersão do tamanho das empresas em relação à média. A alavancagem da empresa demonstra a relação do endividamento da empresa com o ativo total, entretanto, devido ao elevado desvio padrão desta variável, pode-se inferir que uma grande quantidade de empresas possui valores diferenciados ao valor da média, variando entre 0,009 a 144,41.

Quanto ao grau de intangibilidade (GI) e tangibilidade (GT), observa-se que em média as empresas possuem maiores valores de intangíveis do que imobilizado quando comparado com o ativo total. Este resultado demonstra-se como inovador, visto que o grau de investimento em ativos intangíveis pelas empresas ultrapassou aos investimentos feitos em imobilizado nas empresas analisadas.

O retorno da ação (RA) demonstrou média positivo para as empresas analisadas, entretanto, devido ao alto desvio padrão uma gama de empresas possui variação do retorno tanto com valores negativos quanto positivos a cima de 100. Da mesma, a oportunidade de crescimento $(\mathrm{OC})$ que é representado pelo crescimento das vendas, também, se demonstrou em média positivo. Dada esta análise, percebe-se que as empresas em média possuem alavancagem alta, grau de intangibilidade maior que o grau de tangibilidade e retornos positivos de ação e receita.

Tabela 3 - Determinantes da adoção do comitê de auditoria

\begin{tabular}{l|c|c}
\hline \multicolumn{1}{c|}{ Variáveis } & Coefic. & Sig. \\
\hline \multicolumn{1}{c|}{ Constante } & $-4,155$ & 0,000 \\
Tamanho da empresa logaritimizado (TAM) & 0,275 & $0,000^{*}$ \\
Alavancagem da empresa (A) & 0,068 & 0,390 \\
Grau de intangibilidade (GI) & $-0,015$ & 0,692 \\
Grau de tangibilidade (GT) & 0,083 & 0,856 \\
Retorno por ação (RA) & 0,480 & $0,012^{*}$ \\
Oportunidade de crescimento (OC) & 0,244 & $0,089^{*}$ \\
Governança corporativa (GC) & 0,011 & 0,977 \\
Tipo de auditoria (BF) & $-0,823$ & $0,020^{*}$ \\
\hline Sig. Modelo Omnibus & & \\
R quadrado Nagelkerke & & $0,000^{*}$ \\
Teste de Hosmer e Lemeshow & & 0,156 \\
Tabela de classificação & & 0,170 \\
\hline
\end{tabular}

Teste de Hosmer e Lemeshow não deve apresentar-se significativo. * Significativo a $10 \%$.

Fonte: Dados da pesquisa.

Com base na Tabela 3, pode observar que o modelo de regressão logística foi significativo e que a adoção do comitê de auditoria pelas empresas analisadas é explicada $15,6 \%$ pelas variáveis do estudo, essencialmente pelo tamanho da empresa (TAM), retorno da ação (RA), oportunidade de crescimento (OC) e o tipo de auditoria (BF), as quais se demonstraram significativas. O Teste de Hosmer e Lemeshow atendeu o esperado, não sendo significativo e a tabela de classificação dos grupos foi observada por 64,41 .

Em relação às variáveis significativas, pode-se observar que o tamanho da empresa, retorno da ação e oportunidade de crescimento contribuíram para a adoção do comitê de auditoria, enquanto que o tipo de empresa de auditoria teve impacto na não adoção do comitê de auditoria.

Desta forma, com base nestes resultados, percebe-se que quanto maior é o tamanho da empresa, quanto mais há investidores interessados pelas ações da empresa e quanto maior é o crescimento desta no mercado, a tendência é que a empresa adote o comitê de auditoria em sua estrutura, a fim de auxiliar no cumprimento das políticas internas, nos 
controles internos e reportar informações contábeis fidedignas à realidade empresarial. Entretanto, observou-se também que empresas auditadas por Big Four tiveram associação com a ausência do comitê de auditoria, tal resultado pode ser em decorrência da maior qualidade que estas auditorias possuem em realizar suas tarefas, o que contribui para que as empresas não necessitem formalizar o departamento de comitê de auditoria interna na empresa.

Quanto ao achado do tamanho da empresa contribuindo para a formação do comitê de auditoria, também foi verificado por Pincus, Rusbarsky e Wong (1989), Adams (1997), Cunha e Politelo (2013) e Furuta (2010), que estudaram empresas norte-americanas, da Nova Zelândia e brasileiras, evidenciando que quanto maior é a empresa, maior será a tendência de estas adotarem comitê de auditoria.

O resultado da associação positiva entre retorno da ação e presença do comitê de auditoria nas empresas confirma os resultados de Furuta (2010), que, considerando empresas brasileiras, observou que retornos positivos das ações estavam associados com a presença do comitê de auditoria. Isto demonstra que o retorno das ações é um determinante para as empresas adotarem o comitê de auditoria, até mesmo por uma pressão externa oriunda dos investidores, que exigem das empresas maior rigor e controle interno para continuar a negociação com as suas ações, o que faz com que as empresas adotem de forma formalizada o comitê de auditoria.

Quanto ao achado da influência positiva da oportunidade de crescimento da empresa com a presença do comitê de auditoria, Cunha e Politelo (2013) observaram o Conselho de Administração (instância superior aos comitês), que a oportunidade de crescimento da empresa impactou positivamente em as empresas participarem em algum nível de Governança Corporativa.

Por outro lado, o resultado negativo da associação entre comitê de auditoria e auditoria realizada por Big Four, vai de encontro ao verificado por Pincus, Rusbarsky e Wong (1989) e Furuta (2010), os quais observaram em empresas norte-americanas e brasileiras (2005 a 2008), respectivamente, que empresas que eram auditadas por Big For possuíam comitê de auditoria. Desta forma, observa-se uma discrepância de resultados entre os verificados no atual estudo e o de Furuta (2010), visto que ambos analisaram empresas brasileiras, porém obtiveram resultados contrários quanto à influência do comitê de auditoria, o que se sugere o aprofundamento de tal relação em estudos futuros.

\section{CONSIDERAÇÕES FINAIS}

O presente estudo teve por objetivo analisar os determinantes da adoção do comitê de auditoria em empresas brasileiras listadas na B3. Para isto adotou-se procedimentos metodológicos descritivo, documental e quantitativo. A amostra do estudo correspondeu a empresas brasileiras no período de 2010 a 2015, no qual gerou 534 observações analisadas, sendo que 267 se referiram a empresas que possuem comitê de auditoria e as outras 267 observações se referiram a empresas que não possuem comitê de auditoria. Esta classificação de amostra igual para esta presença ou ausência de comitê de auditoria foi necessária para se realizar análise de modelo de acordo com a regressão logística.

Observou-se com base na estatística descritiva, que em média as empresas analisadas possuíam alavancagem alta, grau de intangibilidade maior que o grau de tangibilidade e retornos positivos de ação e receita. Os resultados da regressão logística apresentaram que os determinantes para a adoção do comitê de auditoria de forma voluntária pelas empresas brasileiras analisadas foram o tamanho da empresa, retorno da 
ação e oportunidade de crescimento, enquanto que empresas auditadas por Big Four tiveram associação com a ausência do comitê de auditoria.

Estes resultados revelam que empresas maiores, devido a sua complexidade de atividades e ativos tendem a adotar o comitê de auditoria de forma formalizada a fim de zelar por sua estrutura e contribuir com sua continuidade no mercado. $O$ resultado do retorno da ação revela que empresas com grandes retornos de suas ações possuem pressão possivelmente externa dos investidores de terem boas práticas e controles internos eficazes para continuar sua negociação, o que pode impactar na decisão da empresa de formalizar o comitê de auditoria. Quanto ao achado do impacto da oportunidade de crescimento na formalização do comitê de auditoria, pode-se constatar que empresas que possuem crescimento em suas vendas e que tem a tendência de expansão possuem a prerrogativa de adotar o comitê de auditoria, a fim de que seu crescimento seja controlado de forma eficaz.

Quanto ao resultado da influência negativa do tipo de auditoria com a presença do comitê de auditoria, pode-se inferir que empresas que são auditadas por Big Four possuem a tendência de não apresentar comitê de auditoria, devido à qualidade deste tipo de empresas em realizar auditoria das demonstrações financeiras e quando solicitado dos controles internos, o que pode dispensar a formalização de comitê interno de auditoria pelas empresas analisadas. Entretanto, sugere-se como pesquisa futura o aprofundamento desta relação entre empresa de auditoria e presença do comitê de auditoria nas empresas, a fim de verificar particularidades que estão intrínsecas nesta associação e podem auxiliar nesta explicação.

Os resultados da presente pesquisa corroboram os achados de Pincus, Rusbarsky e Wong (1989), Adams (1997), Furuta (2010) e Cunha e Politelo (2013) no que se refere a empresas maiores terem a propensão de adoção do comitê de auditoria, ou níveis diferenciados de governança corporativa como é o caso do estudo de Cunha e Politelo (2013).

O impacto positivo do retorno da ação em relação a adoção do comitê de auditoria é corroborado pelo estudo de Furuta (2010), o qual constatou em empresas brasileiras também. Quanto ao resultado da oportunidade de crescimento, corroborou com o estudo de Cunha e Politelo (2013), os quais observaram que em empresas brasileiras com oportunidade de crescimento tiveram a propensão de níveis diferenciados de governança corporativa. Já em relação aos resultados da variável Big Four, não corroborou com os achados de Pincus, Rusbarsky e Wong (1989) e Furuta (2010), os quais previram associação positiva com a adoção do comitê de auditoria.

De maneira geral, os resultados da presente pesquisa são complementares com os achados de estudos nacionais e internacionais, no que se refere as variáveis tamanho da empresa (PINCUS; RUSBARSKY; WONG, 1989; ADAMS, 1997; FURUTA, 2010; CUNHA; POLITELO, 2013), retorno da ação (FURUTA, 2010) e oportunidade de crescimento (CUNHA; POLITELO, 2013) como influenciadores da adoção do comitê de auditoria.

Porém, no que se refere a variável Big Four, observou-se resultado diferenciado, uma vez que em outros contextos, como empresas norte americanas antes da SOX (PINCUS; RUSBARSKY; WONG, 1989) e empresas brasileiras até o período de 2008 (FURUTA, 2010) a relação foi positiva e não negativa conforme o observado no atual estudo. Infere-se que esta novidade de resultado, refere-se as empresas brasileiras no período atual (2010 a 2015) concederem preferência a adoção do comitê de auditoria principalmente quando são auditadas por não big four, devido a necessidade de compensar a qualidade da auditoria realizada. 
Observa-se de maneira geral, uma tendência tanto de empresas brasileiras, quanto de empresas estrangeiras dos EUAs (PINCUS; RUSBARSKY; WONG, 1989) e Nova Zelândia (ADAMS, 1997) dos fatores determinantes para a adoção do comitê de auditoria. Este resultado decorre principalmente da universalidade do comitê de auditoria, uma vez que este apresenta de maneira geral, características semelhantes de atuação independente do país, o que torna mais explícitos os fatores que podem impactar em sua adoção.

Indica-se como pesquisas futuras a análise do comitê de auditoria e seus determinantes em relação aos setores de atuação, a fim de identificar particularidades de setores que podem influenciar na adoção de tal comitê. Além disso, indica-se a análise do conselho fiscal em empresas, se este atua como complementar ou suplementar em relação as atividades realizadas pelo comitê de auditoria. Como limitação observou-se a análise do comitê de auditoria somente formalizado nas empresas, sem observar as características de atuação destes a fim de avaliar a sua efetividade, o que pode ser analisado em estudos futuros. Também, não foi analisado legislações específicas de setores que podem impactar na adoção de tal comitê, o que pode ser suprimido em estudos futuros.

\section{REFERÊNCIAS}

ADAMS, M. Determinants of audit committee formation in the life insurance industry: New Zealand evidence. Journal of Business Research, v. 38, n. 2, p. 123-129, 1997.

BAIOCO, V. G.; ALMEIDA, J. Efeitos do comitê de auditoria e do conselho fiscal na qualidade da informação contábil no Brasil. Revista Contabilidade \& Finanças-USP, v. 28, n. 74, p. 229248, 2017.

BELLI, M. M. et al. ANÁLISE DA PERCEPÇÃO DOS EFEITOS DA LEI SARBARNES-OXLEY NAS EMPRESAS BRASILEIRAS QUE POSSUEM ADRS. Revista de Contabilidade do Mestrado em Ciências Contábeis da UERJ, v. 21, n. 3, 2016.

BEUREN, I. M.; NASS, S.; THEISS, V; CUNHA, P. R. Caracterização proposta para o comitê de auditoria no código de Governança Corporativa do Brasil e de outros países. Revista de Educação e Pesquisa em Contabilidade (REPEC), v. 7, n. 4, 2013.

BORGES, A. Gestão de risco e administração de crise: ferramentas essenciais para empresas e investidores. Revista Relações com Investidores, n. 127, p. 10-15, 2008.

BRADBURY, M. E. The incentives for voluntary audit committee formation. Journal of Accounting and public policy, v. 9, n. 1, p. 19-36, 1990.

CORREIA, L. F.; AMARAL, H. F. Arcabouço teórico para os estudos de Governança Corporativa: os pressupostos subjacentes à teoria da agência. Revista de Gestão USP, v. 15, n. 3, p. 1-10, 2008.

CUNHA, P. R.; POLITELO, L. Determinantes do nível de Governança Corporativa das empresas brasileiras de capital aberto do setor de consumo cíclico da BM\&FBovespa. Advances in

Scientific and Applied Accounting, v. 6, n. 2, p. 211-235, 2013. 
DANTAS, J. A.; CHAVES, S. D. M. T.; SOUSA, G. A.; SILVA, E. M. Concentração de auditoria no mercado de capitais brasileiro. Revista de Contabilidade e Organizações, v. 6, n. 14, p. 4-21, 2012.

FREITAS NETO, Raimundo Marciano de; MOL, Anderson Luiz Rezende. Determinants of the Roles Boards of Directors Have in Brazilian Companies. Revista de Administração Contemporânea, v. 21, n. SPE, p. 63-83, 2017.

FURUTA, F. A relação das características das empresas com a adoção do Comitê de Auditoria X Conselho Fiscal adaptado. Tese (Doutorado em Controladoria e Contabilidade). Universidade de São Paulo, USP. São Paulo, 2010.

GOODWIN-STEWART, J.; KENT, P. Relation between external audit fees, audit committee characteristics and internal audit. Accounting \& Finance, v. 46, n. 3, p. 387-404, 2006.

HOGAN, C. E.; WILKINS, M. S. Evidence on the Audit Risk Model: Do Auditors Increase Audit Fees in the Presence of Internal Control Deficiencies? Contemporary Accounting Research, v. 25, n. 1, p. 219-242, 2008.

IBGC - INSTITUTO BRASILEIRO DE GOVERNANÇA CORPORATIVA. Código das melhores práticas de Governança Corporativa. 5. ed. São Paulo: IBGC, 2015.

MENON, K.; WILLIAMS, J. D. The use of audit committees for monitoring. Journal of Accounting and Public Policy, v. 13, n. 2, p. 121-139, 1994.

MURCIA, F.; BORBA, J. Quantificando as Fraudes Contábeis sob duas óticas: Jornais Econômicos Versus Periódicos Acadêmicos no período 2001-2004. Revista de Contabilidade do Mestrado em Ciências Contábeis da UERJ, v. 10, n. 2, p. 99, 2005.

OECD - ORGANISATION FOR ECONOMIC CO-OPERATION AND DEVELOPMENT. Principles of Corporate Governance Principles. 2004. Disponível em:

<https://www.oecd.org/corporate/ca/corporategovernanceprinciples/31557724.pdf>.

Acesso em 16 ago. 2016.

OLIVEIRA, M. C.; COSTA, P. P. O comitê de auditoria nas companhias abertas brasileiras: um estudo multicaso. In: Congresso USP de Controladoria e Contabilidade, n. 5, São Paulo (SP). Anais... São Paulo: USP, 2005.

PELEIAS, I. R.; SEGRETI, J. B.; COSTA, C. A. Comitê de auditoria ou órgãos equivalentes no contexto da Lei Sarbanes-Oxley: estudo da percepção dos gestores de empresas brasileiras emitentes de American Depositary Receipts-ADRs. Contabilidade Vista \& Revista, v. 20, n. 1, p. 41-65, 2009.

PINCUS, K.; RUSBARSKY, M.; WONG, J. Voluntary formation of corporate audit committees among NASDAQ firms. Journal of Accounting and Public Policy, v. 8, n. 4, p. 239-265, 1989. 
SEGRETI, J. B.; COSTA, C. A. Pesquisa exploratória sobre a implantação do comitê de auditoria em empresas Brasileiras conforme a Lei Sarbanes-Oxley. In: EnANPAD, 31, Rio de Janeiro, 2007. Anais... Rio de Janeiro: ANPAD, 2007.

SHARMA, V.; NAIKER, V.; LEE, B. Determinants of audit committee meeting frequency: evidence from voluntary governance system. Accounting Horizons, v. 23, n. 3, p. 245-263, 2009.

VELOZO, E. J.; PINHEIRO, L. B.; SANTOS, M. J. A. D. Concentração de Firmas de Auditoria: atuação das Big Four no Cenário Empresarial Brasileiro. Pensar Contábil, v. 15, n. 58, 2014.

VERA-MUNÕZ, S. C. Corporate Governance Reforms: Redefined Expectations of Audit Committee Responsibilities and Effectiveness. Journal of Business Ethics, v. 62, n. 2, p. 115127, 2005.

WILKS, T. J.; ZIMBELMAN, M. F. Decomposition of Fraud-Risk Assessments and Auditors' Sensitivity to Fraud Cues. Contemporary Accounting Research, v. 21, n. 3, p. 719-745, 2004. 